\title{
BIOLOGÍA FEROMONAL EN LA ESPECIE HUMANA
}

Grégory Alfonso García MD, MSc*, Álvaro Andrés Gaitán**

\section{Resumen}

Las funciones de quimiosensitividad y quimiosensorialidad de la nariz humana han sido siempre despreciadas, pero el incremento de evidencias a partir de investigaciones en otras especies animales sugiere que la olfación puede servir para otros propósitos muy importantes. En mamíferos está mediada por distintos órganos localizados en la cavidad nasal, como el epitelio olfatorio que une moléculas volátiles, responsable de la percepción consciente de olores y el órgano vomeronasal (OVN) que une feromonas y origina varias respuestas sobre todo entre individuos de una misma especie. Moléculas olorosas y feromonas se unen a receptores que permiten la señal de transducción, que son codificados por grandes familias multigénicas. Esta revisión presenta la información reciente y actualizada acerca de la temática de feromonas humanas.

feromona, odor, olfato, órgano vomeronasal, sociobiología.

OVN, órgano vomeronasal; FM, feromona(s); NE, neurona(s).

\section{Abstract}

The chemo-sensitivity and chemosensory functions of the human nose have been regularly disregarded, but increasing evidence obtained from research in other animal species suggests that olfaction may serve other very important purposes. In mammals, olfaction is mediated by several organs located in the nasal cavity such as: the olfactory epithelium that binds volatile molecules and is responsible for the conscious perception of smell (odorants), and the vomeronasal organ (VNO) that binds pheromones and is responsible for various behavioural, reproductive and neuroendocrine responses mainly between members of the same species. Odorants and pheromone molecules bind to receptors that permit signal transduction. These receptors are encoded by large multigene families. This review presents recent and updated information about human pheromone-related issues.

\section{Odor, Pheromone, Sociobiology, Vomeronasal Organ(VNO), Smell.}

Fecha recibido: noviembre 19 de 2007 - Fecha aceptado: enero 18 de 2008

* Docente facilitador. Docente experto en genética, bioquímica y biología celular y molecular. Unidad de Educación e Instituto de Investigación. Facultad de Medicina. Fundación Universitaria UNISANITAS. Docente posgrado. Laboratorio de inmunología clínica.Pontificia Universidad Javeriana. Bogotá D.C. Colombia.

* Res. Sch. Department of medicine/infectious diseases. University of Texas Health Science Center at San Antonio (UTHSCA).

*** Diagramas y esquemas: Giovanny Alexánder Jácome, estudiante de tercer semestre. Facultad de medicina, Fundación Universitaria UNISANITAS. Bogotá D.C. Colombia.

\section{Preludio cultural}

Para comenzar hablemos de los perfumes: "el agua admirable o agua de Regina" fue la primera fragancia creada con fines comerciales, desarrollada en 1725 por el italiano Juan Paulo Feminis y su sobrino Juan María Farina, quienes instalaron en Colonia un laboratorio y tienda para su "Acqua Coloniensis", que llegó a Francia y fue popularizada incluso por Napoleón. ¡He aquí el agua de colonia popular aún hoy en día! ${ }^{1}$ 
Uno de los episodios más hermosos de la literatura francesa lo constituye un fragmento de "En busca del tiempo perdido", una magdalena (bizcocho tradicional francés) en el té permite a Marcel Proust saltar hacia el pasado y reconstruir una vida y una época en que el narrador recobra la memoria de su hijo. ${ }^{2}$ Por lo anterior se denominan los cuadros convulsivos de memoria olfativa como sindrome de Proust. Esto recuerda el famoso sindrome de Stendhal, una entidad psicosomática caracterizada por cambios neurovegetativos autonómicos cuando un individuo observa belleza estética artística.

Resulta curioso que desde tiempos inmemoriales diversas culturas han atribuido propiedades afrodisíacas, es decir activadoras de la líbido, a un sinnúmero de sustancias. El almizcle es una de estas materias primas que se encuentra en forma natural en el buey almizclero, en la rata almizclera de India y Europa, en el pato almizclero del sur de Australia, en la musaraña almizclera, el escarabajo almizclero y en el caimán de América Central, entre otros. También se encuentra en ciertas plantas como el almizcle común (Mimulus inoschalus), en la madera almizclera de las Guyanas y en las semillas del Hibiscus Abelmoschus (semillas de almizcle). Se ha sintetizado en forma artificial desde 1888, pero la variedad que se comercializa es la secreción del ciervo almizclero, extraida de unas glándulas especiales del abdomen, siendo preferido el Tong-king de los himalayas chinos y tibetanos. Algo similar sucede con el ámbar gris que se extrae de la bilis de los mamíferos marinos que llamamos cachalotes y con la algalia, sustancia segregada por una glándula que se ubica cerca al ano del gato de Algalia, que se usa en perfumes, inciensos y pociones, y fue muy famosa durante el siglo XVIII.

La nariz es quizás uno de nuestros órganos sexuales más importantes y socializantes, sin embargo no lo cubrimos...bueno, excepto las musulmanas ortodoxas por medio de la burka o chador afgano o velo islámico, que fue al principio en algunas castas y aún todavía signo de alta posición. ${ }^{3}$

El libro "Das Parfum, die Geschichte eines Mörders" escrito en 1985 por Patrick Süskind y traducido del alemán como "El Perfume", es la historia de un asesino escrita a manera de novela histórica, que muestra la pasión psicopatológica por lo volátil, por la escencia virginal femenina, que es lo que se convierte en el canon de Jean-Baptiste Grenouille, en la Francia del siglo XVIII. ${ }^{4}$ El año pasado se estrenó una soberbia adaptación cinematográfica, dirigida por Tom Tykwer que fue estrenada el 14 de septiembre de 2006 en Alemania. Dicho libro fue la musa inspiradora de las canciones "Scentless Apprentice", del grupo de rock estadounidense Nirvana, de "Du riechst so gut (Hueles tan bien)" de la banda de tanzmetal alemana Rammstein y de "Herr Spiegelmann" del grupo de metal gótico portugués Moonspell. No podemos olvidar boleros que hacen alarde del jolor... del amor!, como "Perfume de gardenias" del maestro Rafael Hernández interpretada en forma magistral por Javier Solís o "Dos gardenias" de Isolina Carrrillo cantada por Daniel Santos.

Un premio Nobel ya fue asignado en 2004 al campo de investigación en la temática olfatoria, al trabajo iniciado en 1991 por Richard Axel y Linda B. Buck, ambos investigadores del Centro de Cáncer Fred Hutchinson (Seattle-EEUU), descubrieron una familia de genes (un millardo) que controlan la producción de receptores específicos para diferentes sustancias. Su trabajo mereció el Premio Nobel de Fisiología y Medicina 2004. ${ }^{5}$ El Dr. David Berliner del Departamento de Anatomía del Colegio de Medicina de la Universidad de Utah, es uno de los pioneros en la caracterización funcional de FM y su recepción en la especie humana, dirigiendo estudios especializados hacia $1991 .{ }^{6,7} \mathrm{El}$ Dr. Berliner es el primero así mismo en comerciar con este conocimiento incipiente y crea la empresa EROX CORP donde patenta dos FM en perfumes para aumentar la atracción sexual. Luego fundó otra compañía PHERIN CORP encaminada a la investigación para usos médicos de las FM.

\section{Introducción}

La previa cita cultural permite traer a colación el quehacer de los olores en nuestra realidad biológica, pero aprovechamos para aclarar que nosotros en esta 
revisión pretenderemos discutir sobre FM y fue difícil en ocasiones encontrar una frontera clara en algunos aspectos en relación con olfato, olor, odor y feromonas, sin embargo, esperamos cumplir tal meta.

Quizás el comienzo del gran interés científico por investigar la temática de las FM fue en la primavera de 1975, cuando la Universidad de Harvard publicó un texto sobre biología social humana y lo llamativo es que era escrito por un científico de hormigas, E.O. Wilson. ${ }^{8}$ Antes en 1962, el grupo de investigación de R. Boch, D.A. Shearer y B.C. Stone aislaron la molécula de iso-amil acetato como una "feromona" de las abejas, y desde ese momento comienza el camino de descubrimientos de sustancias químicas con capacidad de generar comunicación entre los seres de una misma especie e incluso entre individuos de distintas especies, orquestando así ecosistemas. ${ }^{9}$ Claro que E.O. Wilson hizo hipótesis de algo evidente en los insectos y lo aplicó al fenómeno humano. Toda esta temática ha venido a reforzarse en el presente por el descubrimiento de los sincitios microbianos llamados "biofilmes", los cuales son sociedades bacterianas o fúngicas que se encuentran libres o como entidades colonizantes infecciosas, en las cuales se determina una masa microbial diferenciada intercomunicada que forma una superficie y está rodeada por una matriz extracelular especializada. ${ }^{10}$

Las FM son mensajeros inodoros que son captados por los órganos transductores como la nariz y órganos precursores evolutivos similares, con funcionalidad a nivel subconsciente que han sido reconocidos por el papel que juegan en la atracción sexual. En las abejas obreras en particular existe una FM de alarma producida por las glándulas de Nasanov, que se ubican desde el punto de vista anatómico bajo el abdomen. Otras FM son producidas solo por la abeja reina, así por ejemplo, en la secreción de las glándulas mandibulares, congregan y generan colmena. ${ }^{11}$

Feromonas y odor: funcionalidad

En 1968, el término "feromona(s)" es indexado dentro del MeSH (del inglés-Medical Subject Heading
Terms) y se define como sustancias químicas excretadas por un organismo dentro de un ambiente, dirigiendo a través de ellas respuestas del comportamiento o fisiológicas por parte de otros organismos. ${ }^{12}$ El término es acuñado por Karlson y Lüscher y la etimologia de FM proviene del griego y significa "llevo excitación".

Todas las especies de plantas, insectos y animales utilizan una gran cantidad de moléculas para la comunicación a manera de un códice. En las plantas incluso parece ser clave para los procesos de cruce directo o en forma indirecta a través de la atracción de insectos. ${ }^{9,11,13}$ Los vertebrados usan las de este tipo para atracción nupcial, dominancia grupal, marcamiento territorial, señales de alarma (invasión territorial), seguimiento de rastro grupal, manipulación de radio sexual y otras funciones que desconocemos. ${ }^{14,15} \mathrm{Las}$ FM comunican individuos interespecie, favoreciendo la caza o la defensa frente a predadores, en caso tal se denominan allomonas. ${ }^{16,17,18}$

Cada individuo tiene un perfil particular de producción de FM y ello se llama "odor" y hace correlato de su estatus hormonal, inmune, dietario y de flora exocomenzal (bacterias dermatofitas). Así mismo, cada especie tiene un perfil de recepción restringido a FM, en particular de su especie, lo que redunda en su membresía biológica. Fuera de ello, por situaciones epigenéticas aún no conocidas, cada individuo de una especie tiene un perfil muy particular de recepción y producción de FM.

En teoría ya hay evidencia de que cada individuo tiene un patrón individual de FM y la atracción se daría frente a individuos que secretan aquellas FM por las cuales tienen una particular proclividad. Hoy es claro que estas sustancias tienen además la particularidad de inducir cambios conductuales de los individuos y en esa forma se sustenta un código a nivel inconciente, que permite que un individuo en una comunidad biológica pueda comunicar sus estados de ánimo para indicarle al grupo su salud, o bien, para indicar la disponibilidad y compatibilidad sexual. Al respecto de lo último, parece existir una especificidad de género para las FM: los machos no 
responden a las FM producidas por miembros de su mismo género, pero sí afectan a las hembras y viceversa. Esto es evidente en vertebrados ${ }^{18,19}$ lo que ha llevado a estudios de punta en mamíferos ${ }^{20,21,22,23}$ incluyendo primates. ${ }^{21,22,23,24}$

Ya en 1870 Jean-Henri Fabre observó que ciertas polillas machos se desplazaban a distancias de kilómetros hasta llegar a las hembras, atraídos por sustancias emitidas por éstas. Un fenómeno análogo se observó en los gusanos de seda y la primera FM fue identificada en 1956 como un atrayente sexual para las mariposas de este animal, el "bombykol", nombre dado en razón al nombre científico de la especie "Bombyx mori". ${ }^{25}$

\section{La cavidad nasal y quimiorecepción en mamíferos}

La cavidad nasal en mamíferos se ha estimado desde el punto de vista biológico que posee cinco grandes tipos de recepción sensitiva especial:

- Mucosa nasal.

- Órgano septal submucoso de Grüeneberg y su aferencia por el nervio trigémino.

- Nervio trigémino y su aferencia através del ramo medial nasal del ramo etmoidal anterior de la división oftálmica.

- Órgano septal de Masera (grupos de NE sensoriales en la porción ventrocaudal de las cavidades ventilorrespiratorias de la base del septo nasal).

- Órgano vomero-nasal (OVN).

Si bien hay un conocimiento importante de la fisiología de la mucosa nasal así como de la sensibilidad a sustancias amoniacales irritantes por parte de las terminales del nervio trigémino (en el argot médico se denomina quemestesis a la sensibilidad a irritantes nasales), nuestro conocimiento es vago al respecto del OVN y muy pobre en relación con el órgano de Masera y el órgano de Grüeneberg. Al revisar la literatura hay verdaderas contradicciones y vacíos. ${ }^{26,27}$

\section{Las feromonas y el OVN}

Los receptores para FM se localizan en especial, pero no en forma exclusiva, en un órgano especializado de la base del septo nasal denominado OVN (Figura 1). Fue descubierto por F. Ruysch en 1703 y redescubierto hacia 1813 por el anatomista danés Ludvig Jacobson. ${ }^{28}$

Las FM dirigen comportamientos programados genéticamente como el sexual y el de agresión entre individuos específicos (de un mismo linaje familiar genético). Se encarga de traducir el señalamiento feromonal químico en actividad eléctrica neuronal, esto es, potenciales de acción. El OVN es un órgano tubular engastado en el hueso, localizado en forma bilateral en la base del septo nasal, se abre adelante hacia la cavidad nasal o hacia la boca a través del ducto vomeronasal. Se ha encontrado en anfibios y en la mayor parte de los reptiles (órgano de Jacobson de las serpientes) y una buena parte de los mamíferos cuentan con un OVN mientras en los pájaros sólo se ha detectado en su fase embrionaria. En tanto que para la organización zonal neuronal de la mucosa olfatoria se ha detectado un patrón de distribución medio-lateral y dorso-ventral, definiendo cuatro zonas, aún no está claro si ese patrón subyace también a la distribución del OVN.

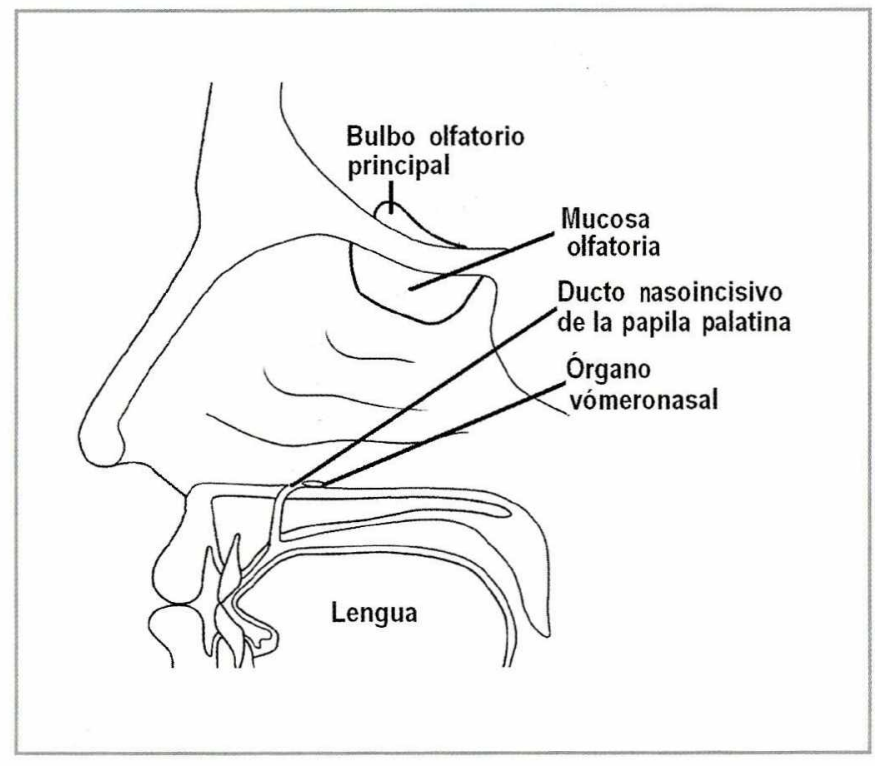

Figura I. Morfología del OVN 
Las FM y su evaluación por parte del cerebro revelan datos sobre:

- El reconocimiento del otro y de su pertenencia grupal; esto da la identificación del yo biológico.

- El estatus biológico de un individuo que tiene funciones claves en la elección de parejas con reproducción viable dentro de un nicho ecológico.

Las actividades desencadenadas por las FM han sido clasificadas en:

- Iniciadoras (del inglés primer): efecto endocrino o neuroendocrino, como el ciclo menstrual.

- Liberadoras (del inglés releasing): efecto sobre el comportamiento, como la atracción sexual y disposición al amamantamiento.

- Señalizadores (del inglés signaler): efecto informativo, como reconocimiento olfatorio del recién nacido por su madre.

- Moduladoras o sugestivas (del inglés modulator): influencia sobre la emoción y la motivación. ${ }^{29,30}$

En vertebrados tetrápodos hay una independencia clara entre el sistema olfatorio y vomeronasal, mientras el sistema olfatorio de los peces teleósteos es aún mixto. Los sistemas de sensorio-sensitividad especial olfatorio, feromonal y gustatorio, son al parecer de los primeros constructos biológicos, fueron primordialmente uno y constituían la unidad de reconocimiento y transducción frente a señales biomoleculares del medio circundante. Después, cuando aparecen grandes organismos multicelulares con especialización tisular, ellos se diversifican y se independizan en forma parcial, puesto que siguen existiendo ciertas finas interacciones neurofuncionales. Evidencia contundente de ello es cuando obliteramos nuestras narinas y degustamos algo, nos puede parecer insaboro o disaboro. El sistema feromonal es muy antiguo y está relacionado de manera directa con estructuras neuroanatómicas subcorticales y basales, en particular con el rinencéfalo. ${ }^{31}$
El ducto vomeronasal también se ha denominado canal o conducto incisivo o nasoincisivo de la papila palatina y hay controversia sobre si en realidad está intercomunicando las dos cavidades y si se encuentra epitelizado. Algunos estudios muestran una alta variabilidad en su existencia y morfología en nuestra especie. ${ }^{32,33,34}$

\section{FM y OVN en la especie humana}

Se ha estimado que una persona es capaz de diferenciar entre diez mil olores diferentes (aunque la gran mayoría de nosotros no podemos nominar esas sensaciones, indicamos que son diferentes). De estas, un porcentaje importante son fuera de ello odoríferas. Aún no está claro cuantos tipos diversos de FM (inodoras) reconocemos. Al respecto de la temática feromonal, la evidencia ni siquiera llega a concluyente en nuestra especie, y esto es porque los mamíferos somos un problema diferente por completo al de los insectos y otros animales de patrón colectivo, donde lo que se denomina como conducta es estereotipada y previsible, por el contrario los humanos somos estructuras conscientes independientes, ingobernables y complejas, la conducta varía en forma amplia y nuestro significado no siempre es evidente y descifrable al observador $\mathrm{y}$ a nosotros mismos. ${ }^{35}$

El OVN es una estructura neuroepitelial superespecializada del epitelio olfatorio, que no es captador de olores sino de odores, es decir, que tiene receptores para captar componentes volátiles que producen los individuos de una especie biológica. Estos odores también han recibido el nombre de "vomeroferinas". El OVN se ha considerado por mucho tiempo una estructura vestigial y su evolución coincide también con la disminución morfofuncional del rinencéfalo. Este último compromete varias neuroestructuras tales como el sistema límbico. En 1937 el neuroanatomista James Papez lanzó la hipótesis que el papel funcional de esta estructura estaba más allá de la sensorialidad olfativa y conformaba la base de la emocionalidad humana. $36,37,38,39$ 


\section{FM y fsiología sexual en la especie humana}

En los animales la conducta sexual está influenciada por señales sexo-específicas, es decir mecanismos químicos como las FM. Estas tan pronto como son captadas por estructuras como el OVN, generan una información que es procesada por núcleos del hipotálamo anterior (área preóptica). ${ }^{40,41}$

Ya en Roma de los gladiadores se comerciaba con el sudor de los hombres. En aquel tiempo no se utilizaba jabón y agua para la higiene personal, se usaba aceite, que se aplicaba a la piel, se frotaba y se masajeaba, luego se extraía por medio de un adminículo especial con forma de espátula en $\mathrm{S}$ o de cepillo metálico con acanaladuras denominado "estrígilo" que permitía su recolección y depósito en recipientes en áreas especializadas de los balnearios públicos, denominados "destrictorium". El aceite usado, sobre todo de oliva, rico en sudor de los luchadores, era apetecido por las damas. Era de mayor costo entre más famoso y victorioso fuera el gladiador. Las mujeres lo aplicaban y lo consideraban un verdadero elíxir de la juventud y un potente estimulador de la atracción sexual. ${ }^{42}$

La androstadienona es el androstene más prominente en la axila humana masculina. Es un esteroide volátil que puede estimular el OVN femenino, produciendo cambios autonómicos. En un llamativo estudio se encontró que la administración directa sobre el OVN resulta en una significativa reducción de la ansiedad, el nerviosismo, tensión y otros estados psicológicos negativos, concordante con cambios fisiológicos autonómicos. ${ }^{43}$

La percepción sensorial a la androstenona, un andrógeno C19 feromonal que es el responsable del olor que se percibe como orina rancia o sudor fuerte, exhibe una gran variación individual, es así que entre los adultos cerca del 50\% reportan no percepción, incluso a altas concentraciones: un $15 \%$ captan un sutil olor y un $35 \%$ son exquisitamente sensitivos, detectando menos de 200 partes por trillón en muestras de aire. ${ }^{44,45}$
El 5alfa-androst-16-en-3alfa-ol (3alfa-androstenol) posiblemente es la FM implicada en la sincronía menstrual que fue descubierta parcialmente en 1971 por McClintock, fenómeno que se presenta entre mujeres que comparten un mismo ambiente familiar y/o laboral, y podría provenir a partir de la sangre menstrual o secreciones vaginales. Esto concuerda con un hallazgo en ratones: la molécula 6-hidroxi6-metil-3-heptanona acelera la presentación de la pubertad en ratones hembra en procesos de sincronización grupal y el alfa-farnesene urinario de los ratones machos promueve lo mismo. ${ }^{46}$

El atractivo físico y la sensación de serlo es importante para la calidad de vida y es en particular clave en las mujeres. En ellas se han efectuado estudios (escogidas dada una disfunción) con FM sintéticas tópicas, mejorando el estado subjetivo de bienestar y la calidad de vida por eventos psicosomáticos neuroendocrinos. ${ }^{47,48,49,50}$ Incluso se ha encontrado un rol para las FM en la neuromodulación frente al dolor. ${ }^{51}$ Esta área aún guarda sorpresas, una de ellas es que algunos estudios evidencian que hay diversidad de respuestas que darían un sustrato fisiológico y natural, tanto al heterosexualismo como al homosexualismo. Sin embargo, es un campo virgen y controversial, sobre todo si se tiene en cuenta que algunas investigaciones han encontrado variaciones morfológicas hipotalámicas. ${ }^{52,53}$

\section{Mecanismos biológicos de acción de las FM}

Las lipocalinas (LCN) son proteínas especializadas en el transporte de sustancias lipófilas y muchas de ellas son al parecer esenciales en biología feromonal. Todas comparten como rasgo familiar el motivo proteico común Gly-X-Trp (Glicina-X-triptófano). El autor y colaboradores efectuamos una revisión sobre la temática de las LCN en biología y patobiología humana..$^{54,55}$

El primer paso en el proceso de olfación de olores al igual que de odores, es la solubilización de moléculas hidrofóbicas en el moco hidrofílico nasal. Allí existen proteínas transportadoras denominadas "proteínas 
unidoras de odorantes (OBP)" las cuales son LCN que unen, transportan y descargan las FM en los receptores presentes en los neuro-olfato-receptores neuroepiteliales. Las OBP son entonces biosensores, de los cuales OBP2A se expresa en estructuras nasales, salivares, lacrimales y pulmonares, mientras que OBP2B tiene mayor expresión en epitelios glandulares alveolares, es decir, las glándulas prostática y mamaria. Ambas OBP se expresan en la placenta y la vas deferens masculina. OBP2A une numerosos odorantes de diversa estructura química pero en especial aldehídos y ácidos grasos de cadena larga. Algunos odorantes se producen en las glándulas sudoríparas apocrinas axilares y las secreciones de este tipo más la actividad de la flora exocomenzal cutánea tanto del hombre como de la mujer, son una fuente de señales que contienen componentes fisiológicos activos y que son capaces de alterar el ciclo menstrual femenino con distintas consecuencias, producto de la regulación del eje hipotálamo-adenohipófisis-gonadal. Esto sucede gracias a la existencia de una proyección directa subneocortical hipotalámica que incluso regula el humor, es decir, la timia. En los hombres el odor feromonal más sintetizado y liberado por los microorganismos axilares es el ácido E-3-metil-2-hexenoico (E-3M2H). La LCN denominada apolipoproteína D (un tipo glicosilada diferecialmente con respecto a su contraparte plasmática) es una proteína unidora y transportadora de $(\mathrm{E}-3 \mathrm{M} 2 \mathrm{H})$. La temática de las LCN en la biología de las FM es aún insospechada, puesto que existen múltiples hallazgos en murinos como ratones, ratas y hámsters que esperan ser demostrados y además ser analizados como propuestas teóricas en sociobiología en la especie humana. Por ejemplo las MUPs (proteínas mayores urinarias) son LCN producidas por el hígado y filtradas para ser eliminadas en la orina, por lo cual se las ha denominado alfa (2U)-globulinas y unen moléculas lipófilas de producción genital, además de que es posible que colaboren en la síntesis y la liberación lenta de estas sustancias odoríferas. Como si fuera poco, una LCN llamada afrodisina en los hámsters, es producida por la vagina de las hembras y ejerce efectos feromónicos en forma directa, estimulando el deseo copulatorio del macho. ${ }^{56,57,58}$

\section{Receptores membranales para FM}

Este sí que ha sido un problema, por cuanto existen moléculas que son oloríferas y odoríferas a su vez, y otras tantas sólo oloríferas u odoríferas. Las NE clásicas de la membrana olfatoria poseen cantidades significativas de cilios apicales luminales y hacen sinapsis con el bulbo olfatorio principal, mientras que las NE de las del OVN poseen microvellosidades y lo hacen con el bulbo olfatorio accesorio. De esa manera, los receptores para señales oloríferas y odoríferas se ubican en especializaciones de la membrana apical de las NE y los receptores para FM se localizarían en $\mathrm{NE}$ del OVN y en menor grado en la zona olfatoria. ${ }^{59,60}$

Otro parámetro molecular considerado fiable era el hecho de que los receptores para sustancias oloríferas se asociaban en forma invariable con dos fenotipos:

- Un sistema de proteínas G trimérico con subunidad G Olf, adenilil-ciclasa tipo III, nucleótido cíclico-fosfodiesterasas PDE1C2 y PDE4A y canales operados por nucleótidos cíclicos CNGA2.

- Un sistema del tipo receptor guanilil-ciclasa tipo $\mathrm{D}(\mathrm{GC}-\mathrm{D})$.

Pero como hay sustancias odoríferas o mixtas (tanto oloríferas como odoríferas) que activan estos sistemas, la situación ya no es tan axiomática.

En el epitelio nasal existe una topografía tal que un set o grupo de receptores se expresa en distintas zonas espaciales, de manera que las NE que expresan el mismo receptor se localizan en la misma zona. Adicional a ello, se encuentra que una NE sólo expresa un alelo de un solo gen en forma estocástica.

El sistema de reconocimiento y respuesta a las FM o receptores para sustancias odoríferas, está constituido por:

- Un receptor membranal del tipo serpentina, es decir, de aquellos que están asociados con un sistema de proteínas $\mathrm{G}$ heterotrimérico (subunidades 
alfa, beta y gamma), denominados "receptores vómero-nasales V-R".

- Un componente proteico que está dado por miembros de la familia de las proteínas denominadas M1/10 (M10.5), las cuales funcionan como chaperones membranales. Son miembros de la superfamilia de los inmunorreceptores de presentación HLA (antígenos mayores de histocompatibilidad) clase $\mathrm{Ib}$.

- Un componente proteico que corresponde al canal TRP2 (del inglés transient receptor potential cation channel) para calcio. TRP2 directamente parece ser un receptor para ciertas FM.

- Proteinas que garantizan la integridad estructural y funcional de la expresión de los receptores para odorantes en la membrana plasmática , como son los miembros de la familia REEP (del inglés-receptor expression enhancing protein 1): REEP1, REEP2, REEP3, REEP4, REEP5 y REEP6 (también denominado DP1L1/TB2L1-del inglés-deleted in polyposis 1-like 1/TB2-like 1), y los miembros de la familia RTP (del inglés-receptor-transporting protein 1): RTP1, RTP2, RTP3 y RTP4 (también denominada IFRG28 del inglés $28 \mathrm{kDa}$ interferon-responsive protein).

Estudios recientes han dilucidado la existencia de una distribución en dos grandes clases de poblaciones celulares de receptores neuronales feromonales (Figura 2):

- La población apical (A) superficial del OVN expresa receptores V1r, sistema de proteínas $G$

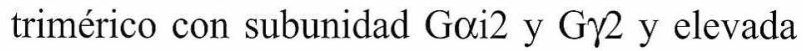
expresión de canales de sodio voltaje dependiente. El axón aferente de estas NE hace sinapsis con la parte anterior del bulbo olfatorio accesorio.

- La población basal (B) profunda del OVN expresa receptores V2r que puede hetero u homo dimerizar, sistema de proteínas $\mathrm{G}$ trimérico con subunidad $\mathrm{G} \alpha 0$ y G $\gamma 8$, miembros de la familia M1/10 con $\beta 2$-microglobulina acompañante y baja expresión de canales de sodio voltaje dependiente. El axón aferente hace sinapsis con la parte posterior del bulbo olfatorio accesorio.
Ambas poblaciones expresan TRP2 y es fundamental recalcar que es activado por medio de una vía dependiente de fosfolipasa $C$ (del tipo isoenzima $\beta$ ) y que el segundo mensajero clave es el 1,2-Di-acil-glicerol (DAG). En razón a lo anterior, hoy es evidente que TRP2 es parte de un canal multisubunitario, el cual es activado por DAG. ${ }^{61}$

Otras poblaciones celulares expresan receptores proteicos que son tanto feromonales como oloríferos. Hoy hay convergencia en pensar que cada receptor interactúa con un amplio rango de compuestos químicos, aunque con distintos rangos de afinidad, así un receptor reconoce múltiples moléculas y una molécula es reconocida por varios receptores, de tal forma que hay una estrategia combinatoria para codificar la información química olorífera y/o odorífera. ${ }^{60}$

\section{Genética, genómica y proteómica de los recep- tores VR}

El problema de los receptores expresados en la mucosa de cavidad nasal es que si bien se han identificado muchos genes en varias especies, se han catalogado bajo la presunción de su similitud en secuencia nucleica y la evidencia de expresión tisular sólo existe para un limitado número de ellos. Como si fuera poco, muchos de estos genes codificantes de moléculas oloríferas y/o odoríferas se expresan en tejidos como los testículos, próstata, células germinales, eritrocitos, corazón y notocorda.

Los receptores VR en mamíferos murinos están representados por dos grandes familias multigénicas: V1r y V2r. Una diferencia estructural génica es que los genes codificantes de V1r no poseen intrones. Una tercera familia ha sido también identificada como V3r. Los VR pertenecen a la clase C de los receptores serpentina, compartiendo familiaridad con los de glutamato, GABA (ácido $\gamma$-amino butírico), calcio (CaSR) y magnesio, gustatorios (TR) y el receptor gustatorio para umami (receptores para glutamato monosódico).

En los murinos existen en promedio 150 genes V1r (agrupados en doce subfamilias), más de 150 genes 


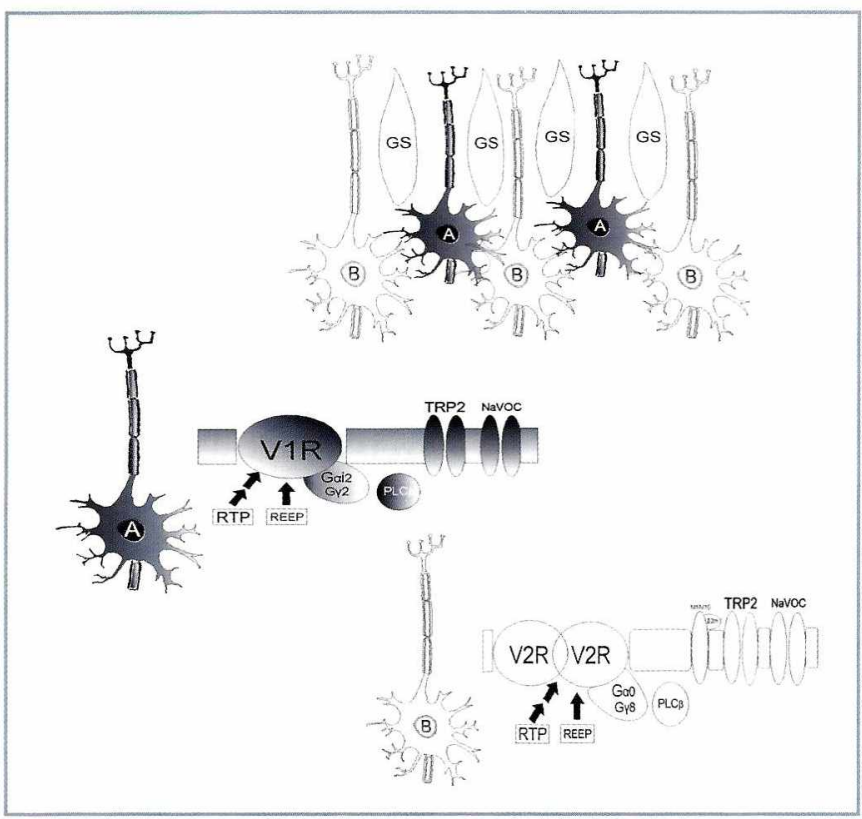

Figura 2. Organización histo-funcional del OVN.

V2r y de 100 a120 genes V3r, distribuyéndose en once regiones diferentes a lo largo de siete cromosomas. Hoy hay claridad total de que V3r es una de las doce subfamilias de V1r, correspondiendo a V1rd. Estos números contrastan con los más de 1.000 a 1.300 genes para receptores olfatorios. La molécula 6-hidroxi-6-metil-3-heptanona es uno de los ligandos para V1r y acelera la presentación de la pubertad en ratones hembra en procesos de sincronización grupal, fenómeno que se ha descrito en múltiples mamíferos y que se ha denominado como efecto Vandenbergh.

En la especie humana (Tabla 1) la situación es la siguiente: se han identificado entre 900 y 1.000 posibles genes, de los cuales el $63 \%$ son pseudogenes. De estas secuencias entre genes y pseudogenes, tenemos como tal:

- En promedio 380 son genes de tipo olfatorio (OR u Olf-R).

- Cinco genes V1r.

- En promedio 410 son pseudogenes de OR.

- En promedio 200 son pseudogenes para V1r.

- No hay evidencia de genes para V2r.

- Existen 20 pseudogenes identificados para V2r.
La búsqueda arroja los anteriores datos, así como curiosidades no explicables como el hecho de que en el cromosoma 20 no se ha evidenciado la existencia de secuencias similares a V1r. Se puede concluir que nuestra especie sólo posee en verdad cuatro genes V1r para captación feromonal, frente a las decenas de genes funcionales V1r y V2r de animales como los murinos. El mecanismo por el cual nuestra especie genera a pesar de ello una gran diversidad de reconocimiento y captación se debe a la existencia de mecanismos de diversificación génica como el corte y empalme alternativo (del inglés Splicing) donde hay barajamiento exónico, o por mecanismos accesorios como la edición del ARN mensajero (del inglés editing).

También se ha encontrado que bajo ciertos mecanismos algunos pseudogenes pueden expresarse. Si lo anterior es así, la expresión de los V2r en el OVN humano podría diversificar la captación y reconocimiento, ya que estos receptores dimerizan entre sí y el hecho de que interactúen con el sistema M1/M10, podría elevar en forma significativa el rango de reconocimiento feromonal. ${ }^{62,63,64,65}$

\section{Otros tipos de receptores}

De los receptores OR (o Olf-R) algunos funcionan a manera de feromonales, como se ha encontrado para el receptor OR1D2 (del inglés olfactory receptor, family 1 , subfamily D, member 2) también denominado OLFR1 (del inglés olfactory receptor 1) o OR17-4, y OR23 (también denominado OR267-13) (Tabla 2 ). ${ }^{66}$

En mamíferos se ha encontrado un grupo de receptores para aminas volátiles, los TAARs (del inglés trace-amine-associated receptors) que también son receptores serpentinas asociados con sistemas de proteínas G triméricos (Tabla 3). Los TAAR se expresan en especial en el órgano submucoso nasoseptal de Grüneberg. La expresión heterogénea de los TAAR se ha demostrado tras la detección de TAAR1 en el corazón, como un receptor endógeno para 3-iodotironamine. ${ }^{66,67,68}$ 


\begin{tabular}{|c|c|c|c|}
\hline $\begin{array}{l}\text { Miembro de la familia VNR (receptor } \\
\text { vomeronasal) } \\
* \text { al final significa que es un pseudogén }\end{array}$ & Código MIM & $\begin{array}{l}\text { Localización } \\
\text { cromosómica }\end{array}$ & Nombres alternos \\
\hline VNIRI & 605234 & $19 q 13.4$ & VNRI9II,VIRLI, ZVNRI, ZVNHI \\
\hline VNIR2 & No definido aun & $19 q \mid 3.42$ & VIRL2 \\
\hline VNIR3 & & $|6 p| 1.2$ & VIRL3, FKSG46 \\
\hline VNIR4 & & $19 q 13.42$ & VIRL4 \\
\hline VNIR5 & & 1944 & VIRL5 \\
\hline VNIR6P & & 19 & VNRI912, ZVNR2, ZVNH2 \\
\hline VNIR7P & & $2 I p \mid I .2$ & ORLPI \\
\hline VNIR8P & & $21 q 11.2$ & ORLP2 \\
\hline VNIR9P & & 22 & VNIR22-IP \\
\hline VNIRIOP & & $6 p 21$ & VNR6IIP, hs6VI-Ip, b24ol 8.2 \\
\hline VNIRIIP & & $6 p 21$ & dj86CII.7, hs6VI-2p,VNR6I2P \\
\hline VNIRI2P & & $6 p 21$ & VNR613P, bA373DI7.2, hs6VI-3p \\
\hline VNIRI3P & & $6 p 21$ & bA373DI7.3, hs6VI-4p,VNR6I4P \\
\hline VNIRI4P & & $6 p 21$ & bA457MII.4, hs6MI-5p,VNR6I5P \\
\hline VN2RIP & & $3 q 25.31$ & CASRLI, GPRC2B \\
\hline VN2R2P & & $5 q 35.3$ & \\
\hline VN2R3P & & $9 p / 3.1$ & \\
\hline VN2R4P & & $9 p / 3.1$ & \\
\hline VN2R5P & & $9 p / 2$ & \\
\hline VN2R6P & & $9 p / 1.1$ & \\
\hline VN2R7P & & $9 q 12$ & \\
\hline VN2R8P & & 9 & \\
\hline VN2R9P & & $|I q| 2.1$ & \\
\hline VN2RIOP & & $16 q 23.1$ & \\
\hline VN2RIIP & & $19 p \mid 3.3$ & \\
\hline VN2RI2P & & $|9 p| 3.2$ & 1 \\
\hline VN2RI3P & & $19 p \mid 3.2$ & \\
\hline VN2RI4P & & $19 p \mid 3.2$ & \\
\hline VN2RI5P & & $19 p \mid 3.2$ & \\
\hline VN2RI6P & & $|9 p| 3.2$ & \\
\hline VN2RI7P & & $19 q 13.43$ & \\
\hline VN2RI8P & & $19 q 13.43$ & \\
\hline VN2RI9P & & $19 q 13.43$ & \\
\hline VN2R2OP & & $21 q 21.2$ & \\
\hline
\end{tabular}

Tabla 2. Genética y genómica de los receptores OR captadores de FM

Nombre

ORID2(del inglés-olfactory receptor, family I, subfamily d, member 2-)

$\mathrm{OR} 2 \mathrm{H} 3$ (del inglés- olfactory receptor, family 2, subfamily h, member 3 -)
Otras nomenclaturas

OLFRI (del inglés-olfactory

receptor I-)

ORI7-4

OLFR2(del inglés-olfactory receptor 2-)
Localización cromosómica

$|7 p| 3.3$

164342

$6 p 21.3$
164342

600578 


\begin{tabular}{|c|c|c|c|}
\hline $\begin{array}{l}\text { Miembro TAAR } \\
\text { *P al final significa que es un } \\
\text { pseudogén }\end{array}$ & Otras nomenclaturas & $\begin{array}{l}\text { Localización } \\
\text { cromosómica }\end{array}$ & Código MIM \\
\hline TAARI & TARI,TAI & $6 q 23.1$ & 609333 \\
\hline TAAR2 & $\begin{array}{l}\text { GPR58(del inglés-G protein- } \\
\text { coupled receptor 58-) }\end{array}$ & $6 q 24$ & 604849 \\
\hline TAAR3 & $\begin{array}{l}\text { GPR57(del inglés-G protein- } \\
\text { coupled receptor 57-), }\end{array}$ & $6 q 23-24$ & No definido aún \\
\hline TAAR4P & - & $6 q 23.2$ & No definido aún \\
\hline TAAR5 & $\begin{array}{l}\text { PNR(del inglés-putative } \\
\text { neurotransmitter receptor-) }\end{array}$ & $6 q 23.2$ & 607405 \\
\hline TAAR6 & TRAR4 & $6 q 23.2$ & 608923 \\
\hline TAAR7P & & $6 q 23.2$ & No definido aún \\
\hline TAAR8 & $\begin{array}{c}\text { TRAR5, } \\
\text { TA5, GPR I02(del inglés- } \\
\text { G protein-coupled receptor 102-) }\end{array}$ & $6 q 23.2$ & 606927 \\
\hline TAAR9 & TRAR3,TA3 & $6 q 23.2$ & 608282 \\
\hline
\end{tabular}

Por último, un tópico aún por investigar son los receptores nucleares, por cuanto muchos de las FM son esteroides y se conocen moléculas esteroideas con actividad neuroesteroidea. El androstenol es un esteroide odorífero del tipo 16-androstene, el cual es desde el punto de vista estructural similar a neuroesteroides endógenos que actúan como positivos moduladores de los receptores GABA (A). En modelos murinos presenta actividad ansiolítica. Aún queda por aclarar si estas FM pueden ser captadas y transportadas desde el OVN hasta el sistema nervioso central. ${ }^{69,70}$

\section{Organización histogenética de la mucosa nasal}

Lo primero que se plantea es que cada gen sea codificante de un receptor y que como tal sean receptores de expresión en la mucosa nasal, y lo que es más, que lo sean para olores y/u odores. Se ha evidenciado una organización bastante singular de los sistemas sensoriales, desde el punto de vista de recepción, así:

- En las NE vomeronasales se expresa un tipo de receptor para uno o un pequeño grupo de ligandos.
- En las NE olfatorias se expresa un solo tipo de receptor para múltiples ligandos.

- En las NE gustatorias se expresan múltiples receptores para moléculas de una misma modalidad (dulce, amargo).

Es fascinante que las NE bipolares (células de Schultze) de la cavidad nasal tienen un mecanismo al parecer estocástico de expresión de un solo gen, valiéndose de mecanismos como la exclusión alélica. Incluso en el OVN, hay una distribución espacial muy particular, de manera que las que expresan el sistema V1r son NE A y las del sistema V2r son $B$.

Existe un "código combinador" en el procesamiento sensitivo a partir de la cavidad nasal, en que las NE que expresan un tipo particular de receptor convergen a uno o dos glómerulos bulbares. Recordemos que los receptores para olores sirven para un amplio tipo de moléculas, mientras que para FM es un grupo más pequeño y restringido, de ahí que esto sumado al procesamiento glomerular bulbar, genere un código singular para cada molécula recibida. ${ }^{71}$ 
Además se pueden esperar variaciones genotípicas en los receptores, las cuales a su vez causan mayores cambios como homozigocidad genética para un receptor, variantes genéticas con productos proteicos que generan receptores con capacidad y especificidad variable, variantes no funcionales no expresables o duplicación génica que eleva la expresión cuantitativa de receptores. . $^{27,63,71}$

Es aún más asombroso que las NE olfatorias en general poseen un ciclo de vida corto, en unos pocos meses se recambia la totalidad del epitelio y esto sucede a lo largo de toda la vida. Tanto las NE periglomerulares como las granulares tienen recambio constante y son reemplazadas por células madre (del inglés Stem cell), las cuales se encuentran en una región por fuera de los bulbos, interiores en relación con las células que revisten los ventrículos de los hemisferios corticales (ependimoglía), región denominada como zona subventricular anterior, desde la cual llegan atravesando lo que se denomina como región de corriente migratoria rostral. A pesar del recambio, las sinapsis y proyecciones se conservan. ${ }^{72}$

\section{Aferencia de los sistemas receptores de la cavidad nasal hacia el sistema nervioso central}

Si bien es claro hoy que muchas moléculas son oloríferas y odoríferas a la vez y que algunas poseen receptores en regiones distintas al OVN, entonces, debemos recalcar que podemos hablar de 3 vías (Figura 3):

1. Las NE receptoras bipolares de la mucosa olfatoria hacen aferencia a las estructuras glomerulares del bulbo olfatorio principal, donde están los penachos dendríticos apicales de las NE mitrales y las de penacho. Luego se puede localizar en histología una capa flexiforme externa formada por las dendritas laterales de las NE mitrales, los cuerpos celulares y las dendritas laterales de NE con penacho y de las granulares. En la capa plexiforme externa priman las sinapsis dendrodendríticas. Después están la capa de los cuerpos de las neuronas mitrales y los axones de capa de los somas de las NE granulares. Los axones de las células mitrales forman el haz denominado tracto olfatorio lateral, que se proyecta hasta los núcleos olfatorios accesorios, el tubérculo olfatorio, la corteza entorrinal y porciones de la amígdala. En general se conocen dos grandes destinos, uno a través de la amígdala lateral hacia la corteza entorrinal y otro hacia la corteza órbitofrontal a través de la corteza piriforme (corteza de tres capas) y el tálamo medio-dorsal. ${ }^{73}$

2. Las NE receptoras bipolares del OVN alcanzan las estructuras glomerulares del bulbo olfatorio accesorio. En el neuroepitelio VN hay una distribución muy especial de NE que se dividen en A y B como ya se comentó. Desde el bulbo olfatorio accesorio se hacen proyecciones hacia la amígdala medial, la cual tiene un circuito bidireccional con el núcleo basal de la estría terminal y también existe una proyección hacia el núcleo arcuato del hipotálamo. ${ }^{74}$

3. La existencia del órgano submucoso de Grüeneberg es aún muy debatida en la especie humana, más que la del propio OVN. El nervio terminal, o también par craneal cero, como ruta aferente feromonal a partir de la posible recepción en el órgano submucoso de Grüeneberg, es un pequeño haz que se encuentra asociado con el nervio olfatorio, localizado a lo largo del borde medial de los bulbos y tractos del primer par craneal. El nervio terminal es un complejo de nervios de un sistema organizado de NE de disposición difusa, en las regiones laterales de la cavidad y tabique nasal. Se proyecta hacia la parte más rostral del cerebro anterior y en su recorrido el nervio presenta uno o más ganglios pequeños que contienen NE uni, bi o multipolares, esparcidas o distribuidas a todo lo largo de su estructura. Las uni y bipolares tienen función sensitiva y las NE multipolares una motora relacionada con el control vasomotor en la región septal. Por la descripción de su recorrido se infiere que el nervio terminal está asociado con el olfatorio, aunque a pesar de la vecindad es funcionalmente diferente, pues en ese sentido se relaciona con la modalidad sensorial, la neuro-modulación, la conducta reproductiva y la función vegetativa, 


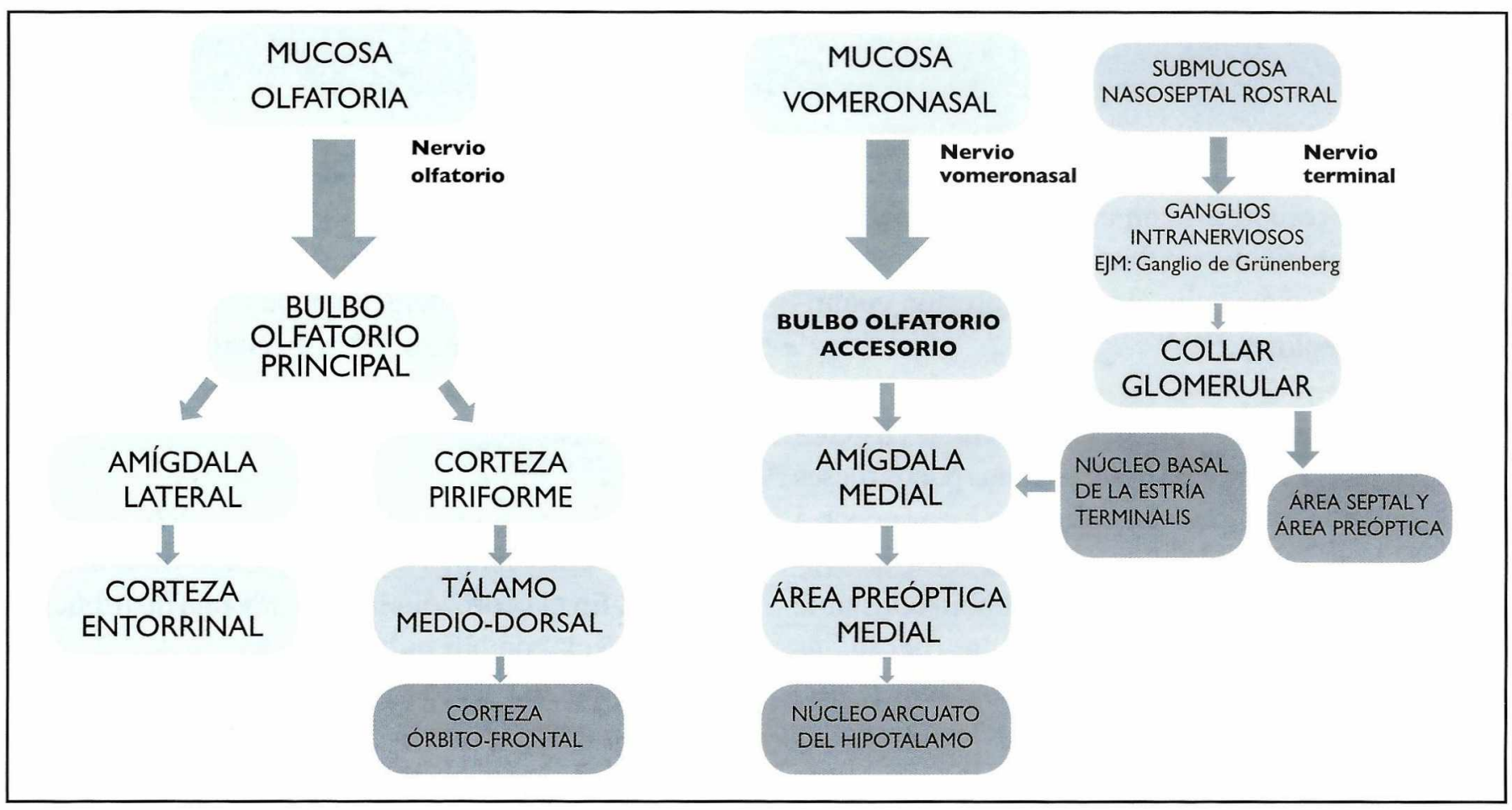

Figura 3. Conexiones aferentes nerviosas.

aspectos que lo diferencian de la función olfativa. La proyección sináptica intermedia se hace hacia los glumérulos del collar glomerular (del inglés necklace glomeruli), estructura conformada por congregados ganglionares dispuestos en la parte rostral del bulbo olfatorio accesorio y la proyección final integradora se efectúa hacia el área preóptica y septal. ${ }^{75}$ Lo que se ha evidenciado en mamíferos inferiores es que los receptores TAAR están en el órgano submucoso de Grüneberg y junto con el hecho de que se han detectado genes y pseudogenes para receptores TAAR en el genoma humano, surge la duda seria de la existencia de este órgano remanente en nuestra especie. ${ }^{66,68} \mathrm{El}$ nervio terminal desde el punto de vista embriológico es el enclave de migración para las células gonadotropas hipotalámicas productoras de GnRH (hormona liberadora de gonadotrofinas), que se originan en la plácoda nasal. Esto último pues, reitera ante todo una relación filogénica entre la actividad feromonal y la función reproductiva-sexual. ${ }^{76,77}$

\section{Genética de la anosmia}

La anosmia es la incapacidad parcial o total de ser sensible a moléculas específicas. Es posible que tal defecto, al igual que en la ceguera neurosensorial, sea producto de un entrecruzamiento genético meiótico desigual (del inglés crossing over), lo que ocasionaría la formación de nuevos receptores híbridos y/o duplicación y/o deleción de genes codificantes de receptores olfativos, gustativos y odoríferos. Así, por ejemplo, se ha encontrado la ceguera al odor primario llamado almizcle, represantado por una pentadecalactona ( $7 \%$ de los caucásicos no son sensibles y tal defecto no se ha hallado en personas negroides), al ácido isovalérico ( $1.4 \%$ de los caucásicos y $9.1 \%$ negroides no son sensibles), a los cianurales (probable patrón recesivo ligado a $\mathrm{X}$ ), al $\mathrm{N}$-butilmercaptano del hedor de las mofetas o zorrillos (posible herencia recesiva), a las flores de fressia (personas del este de Europa, $10 \%$ de los descendientes de británicos célticos y se considera baja en escandinavos, ingleses, daneses y $4 \%$ de los descendientes germanos) y al ácido isobutírico (defecto denominado Davinismo, en honor a Alfred Davis, quien la describió). Así mismo, existe habilidad genética para percibir acetona y metil-etil-cetona (MEK) y se ha encontrado una hipersensibilidad sensorial en ciertos individuos frente al compuesto volátil azufrado denominado como methanethiol, el cual se elimina en la orina en 
particular tras el consumo de espárragos.

En relación con todo esto, el sistema olfatorio ha provisto un modelo de neurodesarrollo único, por cuanto existe un destino preciso para las proyecciones axonales que se originan en las NE sensoriales localizadas en el epitelio olfatorio, hacia NE específicas en los bulbos olfatorios. Esto revela un mapeo sensorio-sensitivo espacial muy refinado, donde hay patrones y pautas de navegación molecular para las NE. Este proceso no es restringido a los estados embrionarios por cuanto sucede durante toda la vida de los mamíferos. Varias moléculas secretadas y de membrana han sido implicadas en la guía y destino de las NE del epitelio olfatorio y vomeronasal, una de ellas bastante especializada, es secretada y se denomina olfactorina, producida a partir del gen UMODL1 (del inglés uromodulin-like 1).

Otra proteína secretada que juega un rol en este proceso es KALLIG1 (también denominada anosmina1), la cual es deficiente por daño de un gen específico en el sindrome de Kallman, que se caracteriza por hipogonadismo hipogonadotrofo hipotalámico y anosmia, y se explica porque las NE gonadotrópicas se originan en la plácoda nasal y luego migran. El síndrome de Kallman también pueden estar causado por daño genético del receptor FGFR1, la prokineticina 2 (PROK2) y el receptor tipo 2 para esta última (PROKR2). ${ }^{78,79}$

\section{FM y espermatogénesis}

E1 receptor odorífero OR1D2 es vómero-nasal y testicular, se expresa en la superficie de los espermatozoides y es necesario para el proceso de quimiotaxis. TRP2 es esencial para la reacción acrosómica. La FM cuyo receptor es OR1D2 corresponde a una molécula fundamental en el olor de los lirios del valle denominada como "bourgeonal". Es curioso que un aldehído correspondiente al undecanal y característico del olor a pegante, compite en forma inhibitoria por OR1D2. Otro receptor feromonal con un comportamiento similar es OR23 (también denominado OR267-13) y sus ligandos en murinos son moléculas pequeñas de naturaleza aldehído. ${ }^{80}$ Este hallazgo sugiere la posibilidad de desarrollar pruebas nasales de fertilidad, además de que el citado receptor puede ser diana para nuevos fármacos anticonceptivos. ${ }^{81,82}$

\section{FM, sexualidad e inmunidad}

El complejo mayor de histocompatiblidad (CMH) es un loci génico en el brazo corto del cromosoma seis cuya función principal radica en la histocompatibilidad y generación de respuesta inmune. Sin embargo, el CMH es una fuente proverbial de odores únicos e individuo-específicos que influencian el reconocimiento individual, preferencias de unión marital, comportamiento nichal y bloqueo selectivo de gestación en animales. Gran parte de estas funciones han sido dificil de reconocer en humanos debido al alto polimorfismo génico.

La función aparente del $\mathrm{CMH}$ al mediar uniones maritales es reducir la presencia de enfermedades en la progenie al promover recombinación y como consecuencia diversidad genotípica y fenotípica en los HLA. También reduce el potencial de endogamia potencializadora de genes recesivos dañados. ${ }^{83,84}$

El CMH ya ha sido implicado en funciones no inmunes en el sistema nervioso central, como el desarrollo y la plasticidad sináptica. Si a esto le sumamos al hecho de que los receptores del tipo V2 están acoplados con moléculas HLA no clásicas como $\mathrm{M} 1 / 10$, solo queda indagar sobre el papel del CMH en biología fermonal. El hallazgo más revelador es que los receptores V2 pueden unir FM peptídicas y que muchas de ellas son péptidos derivados del HLA. Otro dato interesante es que los genes codificantes del receptor OR2H3 y el cluster génico TAAR están en el CMH.

Como corolario se sugiere que el reconocimiento olfatorio y odorífero no está muy lejano del reconocimiento inmune y es probable que así como se hace instrucción tímica, también se haga una neural frente a aquello que en nuestro nicho ecológico se 
reconoce como estatus social y sexual. El fenómeno feromonal es fascinante, así es significativo que las mujeres prefirieren a los hombres con HLA más disímil a los suyos propios, generando diversidad por la no consecución endogámica. ${ }^{85,86}$

\section{Algunas evidencias y hallazgos patobiológicos}

Existe evidencia patobiológica llamativa pero aún no decantada al respecto del rol del OVN como blanco de sensibilidad química, lo que explicaría por qué ciertas alteraciones neuroendocrinas son desencadenadas por algunos tóxicos. ${ }^{87} \mathrm{El} \mathrm{OVN}$ es una posible ruta de invasión y neurotrofismo por parte de ciertos herpesvirus. $^{88}$

\section{Discusión e hipótesis: FM y socialización biológica}

El término vasana ha sido dado a las FM que coordinan el quehacer social de una especie. Entonces, nuestro aire es trascendente no sólo por el oxígeno sino porque es el portador de una gama infinita de informaciones subjetivas. Sentimos placer al conocernos y reconocernos como parte de una entidad más amplia que nosotros y deriva de la función social propia de nuestra especie. El sustrato y orquestador neuroanatómico pilar de la socialización es la amígdala medial. Desde aquí se generan rutas de sinapsis con el núcleo de la amígdala basolateral y el núcleo accumbens para generar cambios en las improntas de memoria de aprendizaje y de comportamiento condicionado; las sinapsis con el núcleo de la amígdala central y el hipotálamo se encargan de generar respuestas neuroendocrinas y autonómicas. La agresión también es un fenómeno procesado por la amígdala, de tal manera que las FM pueden disparar reacciones neuroautonómicas y neuroendocrinas que sustenten los eventos psicosomáticos relacionados con el temor y el miedo, y por ende a respuestas de agresión. Así, el intercambio inconsciente de señales como los odores determinaría el carácter social del hombre. En este siglo se ha comenzado a desglosar el conocimiento del ser psíquico en lo relativo a su individualidad y son rechazables los abordajes científicos que no tengan en cuenta las relaciones entre lo biológico y lo social, porque empobrece la comprensión de lo humano. La neurociencia y la neurobiología inician la acreditación del carácter social del hombre, sin tomar como punto de partida las ciencias sociales. ${ }^{89}$ Hay evidencia del papel socializador familiarizante que podría tener el amamantamiento, por cuanto en la areola existen glándulas apocrinas productoras de $\mathrm{FM}^{90}$

\section{Referencias}

1 Aftel M. Pequeña historia del perfume: la alquimia de las escencias. Madrid: Paidós; 2002.

2. Proust M. En busca del Tiempo Perdido. Madrid: Alianza; 1992.

3. Cuevas C. El pensamiento del Islam. Madrid: Istmo; 1972.

4. Süskind P. El Perfume: historia de un asesino. Barcelona: Seix Barral; 2006.

5. Nobel Foundation [página en Intenet]. Stockholm: The Foundation; c2008 [citado 4 Oct 2007]. The Nobel Prize in Physiology or Medicine 2004; [aprox. 2 pantallas]. Disponible en: http://nobelprize.org/nobel prizes/medicine/laureates/2004/<http://nobelprize.org/nobel_prizes/ medicine/laureates/2004/>

6. Berliner DL, Jennings-White C, Lavker RM. The human skin: fragrances and pheromones. J Steroid Biochem Mol Biol. 1991 Oct;39(4B):671-9

7. Stensaas LJ, Lavker RM, Monti-Bloch L, Grosser BI, Berliner DL. Ultrastructure of the human vomeronasal organ. J Steroid Biochem Mol Biol. 1991 Oct;39(4B):553-60.

8. Wilson EO. Sociobiology: the new synthesis. Cambridge: Harvard University Press; 1975.

9. Boch R, Shearer DA, Stone BC. Identification of isoamyl acetate as an active component in the sting pheromone of the honey bee. Nature. 1962 Sep 8;195:1018-20

10. Callow JA, Callow ME. Biofilms. Prog Mol Subcell Biol 2006;42:141-69.

11. Tittiger C. Functional genomics and insect chemical ecology. J Chem Ecol. 2004 Dec;30(12):2335-58

12. National Center for Biotechnology Information [página en Intenet]. Bethesda: The Center; c2008 [actualizado 14 Abr 2008; citado 4 Oct 2007]. Mesh; [aprox. 2 pantallas]. Disponible en: http://www.ncbi.nlm.nih.gov/sites/ entrez?db=mesh <http://www.ncbi.nlm.nih.gov/sites/ entrez? $\mathrm{db}=$ mesh $>$

13. Ledford H. Plant biology: the flower of seduction. Nature. 2007 Feb 22;445(7130):816-7

14. Sachs JL, Mueller UG, Wilcox TP, Bull JJ. The evolution of cooperation. Q Rev Biol. 2004 Jun;79(2):135-60 
15. Sumpter DJ. The principles of collective animal behaviour. Philos Trans R Soc Lond B Biol Sci. 2006 Jan 29;361(1465):5-22

16. Apfelbach R, Blanchard CD, Blanchard RJ, Hayes RA, McGregor IS. The effects of predator odors in mammalian prey species: a review of field and laboratory studies. Neurosci Biobehav Rev. 2005;29(8):1123-44.

17. Takahashi LK, Nakashima BR, Hong H, Watanabe K. The smell of danger: a behavioral and neural analysis of predator odor-induced fear. Neurosci Biobehav Rev. 2005;29(8):1157-67.

18. Sbarbati A, Osculati F. Allelochemical communication in vertebrates: kairomones, allomones and synomones. Cells Tissues Organs. 2006;183(4):206-19.

19. Brennan PA, Zufall F. Pheromonal communication in vertebrates. Nature. 2006 Nov 16;444(7117):308-15.

20. Brennan PA, Kendrick KM. Mammalian social odours: attraction and individual recognition. Philos Trans R Soc Lond B Biol Sci. 2006 Dec 29;361(1476):2061-78.

21. Smith TD, Bhatnagar KP, Shimp KL, Kinzinger JH, Bonar CJ, Burrows AM, Mooney MP, Siegel MI. Histological definition of the vomeronasal organ in humans and chimpanzees, with a comparison to other primates. Anat Rec. 2002 Jun 1;267(2):166-76.

22. Evans CS. Accessory chemosignaling mechanisms in primates. Am J Primatol. 2006 Jun;68(6):525-44.

23. Mundy NI. Genetic basis of olfactory communication in primates. Am J Primatol. 2006 Jun;68(6):559-67.

24. Snowdon CT, Ziegler TE, Schultz-Darken NJ, Ferris CF. Social odours, sexual arousal and pairbonding in primates. Philos Trans R Soc Lond B Biol Sci. 2006 Dec 29;361(1476):2079-89.

25. Nagasawa H, Kuniyoshi H, Arima R, Kawano T, Ando T, Suzuki A. Structure and activity of Bombyx PBAN. Arch Insect Biochem Physiol. 1994;25(4):261-70.

26. Breer H, Fleischer J, Strotmann J. The sense of smell: multiple olfactory subsystems. Cell Mol Life Sci. 2006 Jul;63(13):1465-75.

27. Witt M, Hummel T. Vomeronasal versus olfactory epithelium: is there a cellular basis for human vomeronasal perception? Int Rev Cytol 2006;248:209-59.

28. Bhatnagar KP, Smith TD. The human vomeronasal organ. V. An interpretation of its discovery by Ruysch, Jacobson, or Kolliker, with an English translation of Kolliker (1877). Anat Rec B New Anat. 2003 Jan;270(1):4-15.

29. Eisthen HL, Wyatt TD. The vomeronasal system and pheromones. Curr Biol. 2006 Feb 7;16(3):R73-4.

30. Witt M, Wozniak W. Structure and function of the vomeronasal organ. Adv Otorhinolaryngol. 2006;63:70-83.

31. Grus WE, Zhang J. Origin and evolution of the vertebrate vomeronasal system viewed through system-specific genes. Bioessays. 2006 Jul;28(7):709-18.

32. Abolmaali ND, Kühnau D, Knecht M, Köhler K, Hütten- brink KB, Hummel T. Imaging of the human vomeronasal duct. Chem Senses 2001;26:35-9.

33. Knecht M, Lundström JN, Witt M, Hüttenbrink KB, Heilmann S, Hummel T. Assessment of olfactory function and androstenone odor thresholds in humans with or without functional occlusion of the vomeronasal duct. hav Neurosci. $2003 \mathrm{Dec} ; 117(6): 1135-41$.

34. Radlanski RJ, Emmerich S, Renz H. Prenatal morphogenesis of the human incisive canal. Anat Embryol (Berl). 2004 Jul;208(4):265-71.

35. Wysocki CJ, Preti G. Facts, fallacies, fears, and frustrations with human pheromones. Anat Rec A Discov Mol Cell Evol Biol. 2004 Nov;281(1):1201-11.

36. Bhatnagar KP, Smith TD, Winstead W. The human vomeronasal organ: part IV. Incidence, topography, endoscopy, and ultrastructure of the nasopalatine recess, nasopalatine fossa, and vomeronasal organ.Am J Rhinol. 2002 NovDec;16(6):343-50.

37. Witt M, Georgiewa B, Knecht M, Hummel T. On the chemosensory nature of the vomeronasal epithelium in adult humans. Histochem Cell Biol. 2002 Jun;117(6):493-509.

38. Smith TD, Bhatnagar KP. The human vomeronasal organ. Part II: prenatal development.J Anat. 2000 Oct;197 Pt 3:421-36.

39. Bhatnagar KP, Smith TD. The human vomeronasal organ. III. Postnatal development from infancy to the ninth decade. J Anat. 2001 Sep;199(Pt 3):289-302.

40. Schober JM, PfaffD. The neurophysiology of sexual arousal. Best Pract Res Clin Endocrinol Metab 2007;21:445-61.

41. Bhutta MF. Sex and the nose: human pheromonal responses. J R Soc Med. 2007 Jun;100(6):268-74.

42. Sigerist H. Hitos en la historia de la salud pública. $5^{\mathrm{a}}$. ed. Madrid: Siglo XXI; 1998.

43. Grosser BI, Monti-Bloch L, Jennings-White C, Berliner DL. Behavioral and electrophysiological effects of androstadienone, a human pheromone. Psychoneuroendocrinology. $2000 \mathrm{Apr} ; 25(3): 289-99$.

44. Wysocki CJ, Beauchamp GK.Ability to smell androstenone is genetically determined. Proc Natl Acad Sci U S A. 1984 Aug;81(15):4899-902.

45. Wysocki CJ, Dorries KM, Beauchamp GK. Ability to perceive androstenone can be acquired by ostensibly anosmic people. Proc Natl Acad Sci U S A. 1989 Oct;86(20):7976-8.

46. Jahanfar S, Awang CH, Rahman RA, Samsuddin RD, See CP. Is 3alpha-androstenol pheromone related to menstrual synchrony? J Fam Plann Reprod Health Care. 2007 Apr;33(2):116-8.

47.Cutler WB, Genovese E. Pheromones, sexual attractiveness and quality of life in menopausal women. Climacteric. 2002 Jun;5(2):112-21.

48. McCoy NL, Pitino L.Pheromonal influences on sociosexual behavior in young women.Physiol Behav. 2002 Mar;75(3):367-75. 
49. Thorne F, Neave N, Scholey A, Moss M, Fink B. Effects of putative male pheromones on female ratings of male attractiveness: influence of oral contraceptives and the menstrual cycle. Neuro Endocrinol Lett. 2002 Aug;23(4):291-7.

50. Friebely J, Rako S. Pheromonal influences on sociosexual behavior in postmenopausal women. J Sex Res. 2004 Nov;41(4):372-80.

51. Villemure C, Bushnell MC. The effects of the steroid androstadienone and pleasant odorants on the mood and pain perception of men and women. Eur J Pain. 2007 Feb;11(2):181-91.

52. Berglund H, Lindstrôm P, Savic I. Brain response to putative pheromones in lesbian women. Proc Natl Acad Sci U S A. 2006 May 23;103(21):8269-74.

53. Martins Y, Preti G, Crabtree CR, Runyan T, Vainius AA, Wysocki CJ. Preference for human body odors is influenced by gender and sexual orientation. Psychol Sci. 2005 Sep;16(9):694-701.

54. Flower DR. The lipocalin protein family: a role in cell regulation.FEBS Lett. 1994 Oct 31;354(1):7-11.

55. García GA, Clavijo D, Mejía O, García A, Vittorino M, Casadiego C, Hernández S, Cobos C, Tovar J, Rey C, Zamudio C. Aspectos biomédicos de la familia de las lipocalinas. Universitas Médica. 2007 Abr;48(2) :118-28.

56. Briand L, Eloit C, Nespoulous C, Bézirard V, Huet JC, Henry C, Blon F, Trotier D, Pernollet JC. Evidence of an odorant-binding protein in the human olfactory mucus: location, structural characterization, and odorant-binding properties. istry. 2002 Jun 11;41(23):7241-52.

57. Beynon RJ, Hurst JL. Urinary proteins and the modulation of chemical scents in mice and rats. Peptides. 2004 Sep;25(9):1553-63.

58. Briand L, Trotier D, Pernollet JC. Aphrodisin, an aphrodisiac lipocalin secreted in hamster vaginal secretions. Peptides. 2004 Sep;25(9):1545-52.

59. Sbarbati A, Osculati F. A new fate for old cells: brush cells and related elements. Anat. 2005 Apr;206(4):349-58.

60. Zarzo M. The sense of smell: molecular basis of odorant recognition. Biol Rev Camb Philos Soc. 2007 Aug;82(3):455-79.

61. Venkatachalam K, Montell C. TRP channels. Annu Rev Biochem. 2007;76:387-417.

62. Feldmesser E, Olender T, Khen M, Yanai I, Ophir R, Lancet D. Widespread ectopic expression of olfactory receptor genes. BMC Genomics. 2006 May 22;7:121.

63. Rouquier S, Giorgi D. Olfactory receptor gene repertoires in mammals. Mutat Res. 2007 Mar 1;616(1-2):95-102.

64. National Center for Biotechnology Information [página en Intenet]. Bethesda: The Center; c2008 [citado 4 Oct 2007]. OMIM - Online Mendelian Inheritance in Man; [aprox. 2 pantallas]. Disponible en: http://www.ncbi.nlm. nih.gov/sites/entrez?db=OMIM\&itool=toolbar <http:// www.ncbi.nlm.nih.gov/sites/entrez?db=OMIM\&amp;ito ol=toolbar>
65. Hugo-international.org [página en Internet]. London: The Human Genome Organisation; c2004-05 [citado 10 Oct 2007]. Disponible en: http://www.hugo-international. org/index.htm

66. Chiellini G, Frascarelli S, Ghelardoni S, Carnicelli V, Tobias SC, DeBarber A, Brogioni S, Ronca-Testoni S, Cerbai E, Grandy DK, Scanlan TS, Zucchi R. Cardiac effects of 3-iodothyronamine: a new aminergic system modulating cardiac function. FASEB J. 2007 May;21(7):1597-608.

67. Fleischer J, Schwarzenbacher K, Breer H. Expression of trace amine-associated receptors in the Grueneberg ganglion. Chem Senses. 2007 Jul;32(6):623-31.

68. Hashiguchi Y, Nishida M. Evolution of trace amine associated receptor (TAAR) gene family in vertebrates: lineage-specific expansions and degradations of a second class of vertebrate chemosensory receptors expressed in the olfactory epithelium. Mol Biol Evol. 2007 Sep;24(9):2099107.

69. Domínguez-Salazar E, Portillo W, Baum MJ, Bakker J, Paredes RG. Effect of prenatal androgen receptor antagonist or aromatase inhibitor on sexual behavior, partner preference and neuronal Fos responses to estrous female odors in the rat accessory olfactory system. Physiol Behav. 2002 Mar;75(3):337-46.

70. Kaminski RM, Marini H, Ortinski PI, Vicini S, Rogawski MA. The pheromone androstenol (5 alpha-androst-16-en-3 alpha-ol) is a neurosteroid positive modulator of GABAA receptors. J Pharmacol Exp Ther. 2006 May;317(2):694703.

71. Johnson BA, Leon M. Chemotopic odorant coding in a mammalian olfactory system. J Comp Neurol. 2007 Jul $1 ; 503(1): 1-34$.

72. Quiñones-Hinojosa A, Chaichana K. The human subventricular zone: a source of new cells and a potential source of brain tumors. Exp Neurol. 2007 Jun;205(2):313-24.

73. Kay LM, Sherman SM. An argument for an olfactory thalamus. Trends Neurosci. 2007 Feb;30(2):47-53.

74. Dulac C, Wagner S. Genetic analysis of brain circuits underlying pheromone signaling. Annu Rev Genet 2006 Dec;40:449-67.

75. Storan MJ, Key B. Septal organ of Gruneberg is part of the olfactory system. J Comp Neurol. 2006 Feb 10;494(5):83444.

76. Duque Parra J, Duque Parra CA. Nervio terminal: el par craneal cero. MedUNAB 2006 Dec;9(3):246-9.

77. Schwarting GA, Wierman ME, Tobet SA. Gonadotropinreleasing hormone neuronal migration. Semin Reprod Med. 2007 Sep;25(5):305-12.

78. Holbrook EH, Leopold DA. An updated review of clinical olfaction. Curr Opin Otolaryngol Head Neck Surg. 2006 Feb;14(1):23-8.

79. Cadman SM, Kim SH, Hu Y, González-Martínez D, Bouloux PM. Molecular pathogenesis of Kallmann's syndrome. Horm Res. 2007;67(5):231-42. 
80. Spehr M, Schwane K, Riffell JA, Zimmer RK, Hatt H. Odorant receptors and olfactory-like signaling mechanisms in mammalian sperm. Mol Cell Endocrinol. 2006 May $16 ; 250(1-2): 128-36$.

81. Spehr M, Hatt H. hOR17-4 as a potential therapeutic target. Drug News Perspect. 2004 Apr;17(3):165-71.

82. Spehr M, Hatt H. A potential role of odorant receptor agonists and antagonists in the treatment of infertility and contraception. Curr Opin Investig Drugs. 2005 Apr;6(4):364-8.

83. Gilad Y, Bustamante CD, Lancet D, Pääbo S. Natural selection on the olfactory receptor gene family in humans and chimpanzees. Am J Hum Genet. 2003 Sep;73(3):489501 .

84. Jacob S, McClintock MK, Zelano B, Ober C. Paternally inherited HLA alleles are associated with women's choice of male odor. Nat Genet. 2002 Feb;30(2):175-9.

85. Olson R, Dulac C, Bjorkman PJ. MHC homologs in the nervous system--they haven't lost their groove. Curr Opin Neurobiol. 2006 Jun;16(3):351-7.

86. Slev PR, Nelson AC, Potts WK. Sensory neurons with MHC-like peptide binding properties: disease consequences. Curr Opin Immunol. 2006 Oct;18(5):608-16.

87. Greene GJ, Kipen HM. The vomeronasal organ and chemical sensitivity: a hypothesis. Environ Health Perspect. 2002 Aug;110 Suppl 4:655-61.

88. Mori I, Goshima F, Ito H, Koide N, Yoshida T, Yokochi T, Kimura Y, Nishiyama Y. The vomeronasal chemosensory system as a route of neuroinvasion by herpes simplex virus. Virology. 2005 Mar 30;334(1):51-8.

89. Synnott A. Sociologia del olor. Rev Mex Sociol 2003 Abr;65(2):431-464.

90. Spencer NA, McClintock MK, Sellergren SA, Bullivant S, Jacob S, Mennella JA. Social chemosignals from breastfeeding women increase sexual motivation. Horm Behav. 2004 Sep;46(3):362-70.
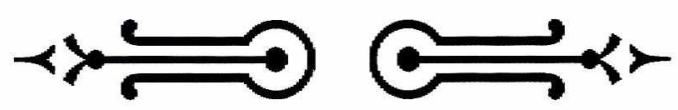